American Journal of Qualitative Research

June 2020, Vol.4 No. 1, pp. 38-48

https://doi.org/10.29333/ajqr/8210

(C) 2020 AJQR. http://www.ajqr.org
AMERICAN

JOURNAL OF QUAUTATIV

RESEARCH

ISSN: $2576-2141$

\title{
Nollywood Reception Preferences among Selected Multilingual Nigerian Undergraduates in the University of Ibadan: Does Ethnicity Still Matter?
}

\author{
Ifeoluwa Theophilus Akinsola ${ }^{1}$ \\ University of Ibadan, Ibadan, Nigeria
}

\begin{abstract}
Multilingualism and multi-ethnicity realities in Nigeria informed the existence of regional Nigerian films (Yoruba, Hausa and Igbo films as majors), apart from English Nollywood films. These regional Nollywoods mainly portray the experiences and lives of people of their regional affiliates and are mostly patronised by indigenes of the regions. As such, this study investigated if such ethnic mindset matters in Nollywood reception preferences among Nigerian undergraduates that are proficient in English and at least two major Nigerian languages. The study, guided by two research questions, adopted the qualitative research design. Fifteen (15) multilingual undergraduate students of the University of Ibadan were purposively selected for a semi-structured interview. The interviews were recorded, transcribed and thematically analysed. Findings revealed that the selected multilingual Nigerian undergraduates, despite their linguistic reality, showed preferences for Nollywood produced in English and/or pidgin above regional ones produced in indigenous languages. The reasons for this, emanating from the sub-themes, were far from ethnicity. Ethnicity, therefore, does not influence Nollywood reception preferences among undergraduates. On this basis, recommendations were made on how Nollywood could be better improved to showcase the nature of Nigeria's unity in diversity.
\end{abstract}

KEYWORDS: Ethnic Mindset, Multi-ethnicity, Multilingualism, Nollywood, Nollywood Reception.

\section{Introduction and Problem Statement}

Nigeria, as a nation, came to being in 1914 with the amalgamation of the Southern and Northern protectorates by the then British colonial master. Hence, Nigeria is, ironically, a fusion of many non-identical regions, which however, have some things in common. Nigeria has been recognised as a land of more than 500 languages and hundreds of ethnic groups. Hausa is the largest group with $25.1 \%$ of the Nigerian population, followed by Yoruba (21.0\%), Igbo (18.0\%), Ijaw (10.0\%), Kanuri (4.0\%), Fulani (3.9\%), Ibibio (3.5\%) and Tiv (2.5\%), while other minority ethnic groups constitute the remaining $12 \%$ of the Nigerian population (WorldAtlas, 2019). Similarly, the Ethnologue of World's Languages totalled Nigerian languages into 525, showing that Nigeria

\footnotetext{
${ }^{1}$ Corresponding; Department of Arts and Social Sciences Education, E-mail: ifeoluwa.akinsola@ gmail.com
} 
consists of hundreds of ethnic groups since many of her indigenous languages are ethnic-based (Ethnologue, 2019). For instance, Hausa, Igbo, Yoruba, and Fulfulde are indigenous Nigerian languages spoken by people of the Hausa, Igbo, Yoruba and Fulani ethnic groups respectively.

Therefore, ethnicity is intrinsically related to language diversity that characterises the Nigerian linguistic environment (Adeyinka \& Akinsola, 2017). Ethnicity has been defined by Osaghae (1995, p. 11) as "the employment or mobilisation of ethnic identity and difference to gain an advantage in situations of competition, conflict or cooperation". Reacting to this definition, Ukiwo (2005) affirmed that the definition is preferred because it identifies two issues that are central to any discussions on the concept of ethnicity. While the first issue is that ethnicity is neither natural nor accidental, but a product of the conscious effort of social actors, the second sees ethnicity beyond its conflictive or competitive manifestations to its cooperative impacts. Thus, Ukiwo (2005) submitted that ethnicity need not always have negative consequences. Similarly, Nnoli (1978, p. 5) sees ethnicity as:

... A social phenomenon associated with the identity of members of the largest possible competing communal groups (ethnic groups) seeking to protect and advance their interest in a political system. The relevant communal factor may be language, culture, race, religion and/or common history. (p. 5)

From Nnoli's point of view, ethnicity could be summed up as the behaviour and every other socio-cultural feature of a particular ethnic group that makes it distinct from other groups. According to this, Blench (2012), and Akpan (2018) observed that language maps illustrated the distribution of ethnic groups and that it would indeed be disingenuous to claim that there are no general correspondences between language and ethnic distribution, especially in the case of minority groups. However, not only are the minority groups linguistically identifiable, even the three major ethnic groups, constitutionally defined in Nigeria with the yardstick of population, are called by their respective language -Yoruba, Hausa and Igbo.

Consequently, Nigeria as a multi-ethnic nation is invariably and equally a multi-lingual nation because many languages, both foreign and indigenous, co-exist. Emenanjo (2002) opined that Nigeria should rather be referred to as a country of a diverse nation and not a nation because of her multi-ethnic, multi-cultural and multi-lingual nature. Ethnic reality is responsible for the multi-lingual reality, hence, Nigeria has many languages in existence since many ethnic groups are co-existing. Upon this reality, Nigerians are encouraged to be multilingual to foster unity, understanding and smooth relationship among Nigerians of varying groups. This is vividly seen in the Nigeria's National Policy on Education which recommended that every student at the junior secondary education level should learn French and another Nigerian language apart from his/her mother tongue, as core subjects (Federal Government of Nigeria, 2004), though observations revealed that the policy is poorly implemented. Similarly, it is observed that the National Youths Service Corps in Nigeria is also programmed towards marking Nigerian youths to be more multicultural and less ethnic-biased. For these reasons and many more, a few Nigerians are multilingual, having more than one Nigerian language in their linguistic repertoire.

Multilingualism refers to the ability one has to effectively make use of two or more languages. Kachru (1986, p. 159) described multilingualism as the "linguistic behaviour of the members of a speech community which alternately uses two, three or more languages depending on the situation and function." Clyne (2007) explained that the phenomenon could refer to either the language use, the competence of an individual to use multiple languages or the language 
situation in an entire nation or society. Therefore, any nation/society that is multilingual should have multilingual citizens. Nigeria is a good example of such a society, as pointed out earlier. As such, a multilingual Nigerian, in the context of this study, is that Nigerian citizen who understands English, his/her mother tongue and at least another Nigerian language.

It should be noted, at this juncture, that multi-ethnicity and multilingualism realities in Nigeria have influenced almost all aspects of Nigerians' life. For instance, the realities have translated into a national policy of education that favours multilingualism. Similarly, the entertainment sector is not left uninfluenced. Nollywood, which is the focus of this study, is highly influenced by the multi-ethnic and multi-lingual realities in Nigeria. This could be extrapolated by the origin and development of and language use in Nollywood films.

The emergence and development of Nigerian films have been categorised into and explained based on three phases - the Colonial/Independence period; the Post-independence period; and the Post-indigenisation Decree period (Ekwuasi, 1991; Olayiwola, 2011). These phases are germane to this present study. During the colonial era, films were mainly foreign and instruments in the hand of the colonial masters to propagate their views and mission in the country (Ahmed, 2016; Olayiwola, 2011; Omolola 2013). However, upon independence in 1960, Nigeria needed to re-define her geographical entity and build a new consciousness of being a nation, to divorce herself from the colonial framework that she had previously been pivoted on (Olayiwola, 2011). This movement gave rise to the establishment of a film division under the Federal Ministry of Information and funded to produce documentary films about post-independent Nigeria, a development that led to the production of locally-made documentary films unlike the imported ones, as submitted by Olayiwola (2011). However, Olayiwola reported that:

...indigenous language films did not come until April 1975 when Amadi produced by Afrocult Foundation Limited was released with impressive success. ... the success soon heralded two other films in indigenous languages: Ajani Ogun (1976) in Yoruba language and Sheu Umar (1977) in Hausa. (Olayiwola, 2011, p. 185)

It could be extrapolated from the foregoing that Nigerian films have been regional or ethnicoriented right from its early and/or developmental stage. Therefore, regional Nigerian films are representing the major ethnic groups - Hausa, Igbo and Yoruba and other groups like Fulani, Igala, Edo, Ibibio, Efik, Tiv and others. Such regional films are produced by descendants of the region and in the indigenous language of the region. By implication, the films would show the life/culture of the region and the major audience of such films would be the indigenes of the region/ethnic group. However, there is still an entity referred to as Nollywood, which captures the Nigerian film industry as a whole. Hence, all the regional Nigerian films and English Nollywood are subsumed under the term Nollywood. Nollywood has developed to such an extent that Nigeria, in 2009, was rated second in the world, next to India, in a UNESCO survey-based only on the quantity of the video-films produced (Alamu, 2010; Bakalar, 2017; Ozfidan \& Burlbaw, 2016). Today, films are released in Nigeria almost every day and are received by both old and young Nigerian citizens. However, ethnic mindset could influence what type of Nollywood (English or Regional) a Nigerian prefers or is receptive to. This is because the regional films are produced in indigenous languages and they showcase regional culture, just as language remains a key identity of an ethnic group. This study was therefore carried out to investigate if such ethnic mindset influences the Nollywood reception preference among Nigerian undergraduates who are linguistically affiliated to more than one ethnic group in Nigeria. 


\section{Empirical Review of Literature}

Some previous studies on Nollywood audience and reception preferences have some similarities with this present study, hence, they are worthy of note. The study of Adeleke (1995) was focused on the reception of Yoruba films by audience members in Ibadan city. The study gathered primary data using a bilingual interview schedule and secondary data from radio and television programmes and advertisements. The study identified the physiological, sociological and psychological factors that determined audience response to the Yoruba films and variation in audience film reception. Among others, the study also indicated that male, youths and literate individuals dominated the Yoruba film audience. Although the study was on audience response to Yoruba films, it has been a strong foundation for further studies on film audience, film reception, audience attitude to and preference for films in the context of regional movies and the Nigerian films (Nollywood) as a whole.

Akpabio (2007) investigated audience attitude to Nollywood films by probing the relationship between audience views and those expressed by critics and experts, who have severely criticized Nollywood for placing too much emphasis on occultism, blood, gore and appeals to the lowest common denominator. Akpabio's finding revealed that the audience has a favourable attitude to Nollywood despite the emphasis on negative themes. Similarly, Onuzulike (2016) juxtaposed two audiences - Nigerians in Nigeria and Nigerians in South Africa to ascertain their perception of aspects of Nigerian movie productions, popularly known as Nollywood. He found that though the two groups favour the depiction of Nigerian/African cultures over other themes, Nigerians in South Africa disfavour the reality of Nollywood movies for reasons of repetition, poor quality and the supernatural. Elegbe and Fadipe (2017) examined audience preference for Yoruba films and how they have promoted their cultural and behavioural values. It was reported in the study that the audience favoured certain Yoruba films, casts, producers and themes, as such factors are indices that determined audience preference for Yoruba movies.

Umezinwa (2012) empirically examined the perceptions of Nnamdi Azikwe University's students' about Nollywood movies and found that students were highly exposed to and showed a high preference for Nollywood films, unlike its foreign counterparts. Umezinwa's findings further revealed that the selected higher institution students did not prefer Nollywood for cultural or regional purpose, though the dressing style of Nollywood actors and actresses greatly influenced them. This is similar to Okeoma's (2012) study, who also found that Nollywood reception among higher institution students in Imo State had a significant influence on students' dress pattern, since the students reported that they are, most times, interested in dressing like Nollywood actors and actresses of whom they are fans.

Alawode and Fatonji (2013), in their content analysis of 50 Nollywood films, found and submitted that though Nollywood portrays Nigerian cultures and aspect of life, they most times bastardise the same because their portrayals are often flawed with exaggerations of flamboyance, affluence and elegance, which were often imbued with an exposition of corruption, violence, ritualism, thuggery and hooliganism as well as witchcraft, occultism/cultism and so on. The study established that Nigerian filmmakers have not been portraying indices like national flags, currencies, coat of arms and so on that could bring about national consciousness into Nigerian film audience. Contrarily, Umar and Mathew (2014), through the lens of technology determinism theory, submitted that Nollywood has helped in propagating national development since societal and national values are being propagated by Nollywood. 
However, these previous researches, and others that could not be reviewed for limited time and space, have not been concerned with the influences of multilingualism and multi-ethnicity on Nollywood reception preferences among Nigerian audience, although the emergence and development of Nollywood are intrinsically linked with indigenisation and regionalisation. Therefore, this present study was carried out to fill the gap by investigating if ethnicity still matters in Nollywood reception preferences among selected multi-lingual Nigerian undergraduate students of the University of Ibadan.

\section{Research Questions}

This study answered the following research question:

1. Which type of Nollywood films (English or Regional) do multilingual undergraduates of the University of Ibadan prefer? And Why the preference?

\section{Methodology}

This study adopted a descriptive qualitative method of data collection and analysis, since the nature of this study was to investigate the 'what' and 'why' of undergraduates' preferences for Nollywood films. The population of the study comprised all undergraduate students of the University of Ibadan. The sample size of 15 undergraduate students was selected from this population. First, the simple random sampling technique was used to select five non-languagebased faculties (Sciences, Social Sciences, Basic Medical Sciences, Law and Technology). From each of the five faculties, the purposive sampling technique was used to select three (3) undergraduate students. In summary, 15 undergraduate students of the University of Ibadan were purposively selected for a semi-structured interview in this study. In line with the focus of this study, the criteria for the purposive selection of these 15 participants were that such student must be:

(i) at least 18 years of age;

(ii) multilingual - an individual who has more than two languages in his linguistics repertoire, that is English and at least two other Nigerian languages;

(iii) a fan/lover of Nollywood films; and

(iv) willing to partake in the study by granting the researchers an interview audience.

Based on these criteria, the socio-demographic characteristics of the nine selected youths are tabulated below:

Table 1

The Socio-demographic Characteristics of the Participants

\begin{tabular}{|c|c|c|c|c|c|c|}
\hline Participant & Gender & Faculty & $\begin{array}{l}\text { Age (in } \\
\text { Years) }\end{array}$ & $\begin{array}{l}\text { State of } \\
\text { Origin }\end{array}$ & $\begin{array}{l}\text { Mother } \\
\text { Tongue }\end{array}$ & $\begin{array}{c}\text { Other Languages } \\
\text { Spoken }\end{array}$ \\
\hline 1. & Female & Technology & 19 & Benue & Igala & $\begin{array}{l}\text { English, Hausa and } \\
\text { French }\end{array}$ \\
\hline 2. & Female & Sciences & 22 & Оуо & Yoruba & English, Hausa \\
\hline 3. & $\begin{array}{l}\text { Male } \\
\text { Female }\end{array}$ & $\begin{array}{c}\text { Social Sciences } \\
\text { Law }\end{array}$ & $\begin{array}{l}20 \\
18\end{array}$ & $\begin{array}{l}\text { Imo } \\
\text { Delta }\end{array}$ & $\begin{array}{l}\text { Igbo } \\
\text { Urhobo }\end{array}$ & $\begin{array}{l}\text { English, Yoruba } \\
\text { English. Edo. Igbo }\end{array}$ \\
\hline
\end{tabular}




\begin{tabular}{|c|c|c|c|c|c|c|}
\hline 5. & Male & Social Sciences & 20 & Kastina & Hausa & English, Fulfulde \\
\hline 6. & Male & Social Sciences & 24 & Oyo & Yoruba & English, Hausa \\
\hline 7. & Male & Sciences & 19 & Enugu & Igbo & English, Edo, Yoruba \\
\hline 8. & Male & Basic Medical Sci. & 18 & Adamawa & Fulfude & English, Hausa \\
\hline 9. & Female & Basic Medical Sci. & 19 & Ebonyi & Igbo & English, Yoruba \\
\hline 10. & Male & Sciences & 18 & Oуо & Yoruba & English, Hausa \\
\hline 11. & Female & Law & 18 & Оуо & Yoruba & English, Hausa \\
\hline 12. & Female & Technology & 21 & Kano & Hausa & English, Yoruba \\
\hline 13. & Female & Basic Medical Sci. & 19 & AkwaIbom & Ibibio & English, Yoruba \\
\hline 14. & Male & law & 20 & Anambra & Igbo & English, Yoruba \\
\hline 15. & Female & Technology & 22 & Bauchi & Hausa & English, Fulfulde \\
\hline
\end{tabular}

A semi-structured interview was conducted with the fifteen (15) selected participants, using an interview guide prepared by the researcher. The interview guide was divided into two sections to cover the two research questions posed to guide the purpose of this study. While nine (9) participants were interviewed physically, the other six (6) were interviewed via the mobile phone. The interview sections were recorded and thereafter transcribed accordingly. The field notes arising from the transcription of the interview were categorised into themes and sub-themes to answer the two research questions posed. The findings of this study arising from the thematic analysis of the data collected are presented in the next section of this paper.

\section{Findings}

\section{Undergraduates' Preference for Different Types of Nollywood Films}

In respect to the first research question raised to guide the study, all the selected undergraduates reported that they are Nollywood fans. They were so passionate about watching Nollywood films that they claimed to have many on their mobile phones and tablets and visit the cinema to watch Nollywood films. One of the participants specifically said:

Na Naija films sweet pass now. Mo máa ń gbádùn è gan-an ... the only movies I get for my laptop na Nollywood. I also spend my leisure time visitng the cinema so as to watch Naija movies...

(Nigerian films are more interesting. I enjoy it so much ... I only have nollywood movies on my laptop. I also spend my leisure time visiting the cinema so as to watch nollywood movies)

However, further findings revealed that the selected multilingual Nigerian undergraduate students of the University of Ibadan, despite their linguistic reality, showed preferences for Nollywood produced in English and/or pidgin above regional ones produced in indigenous languages. This was revealed by their responses to research question one. Though they were direhard fans of Nollywood and were aware of various types of Nollywood films, their responses showed that the Nollywood films that they are most receptive to are the ones produced either in English, Pidgin or both. They claimed they possessed and have watched more English Nollywood 
than regional ones. Similarly, most of the selected participants claimed to be dire-hard fans of English Nollywood stars like Ini Edo, Mercy Johnson and so on as they follow them religiously on the social media platforms like Instagram, Facebook, Twitter and the likes. The words of one participant interestingly buttress this position:

\section{I like Nigerian films like ..., especially the ones produced by English actors ... in fact, I'm a fan of Ini Edo, Mercy Johnson ... I also like jeniffer, especially for her Jenifa's diary. I follow most of the English nollywood actors on Instagram. I can spend my last card to visit the cinema if the film features Ini Edo.}

Additionally, based on the conducted interview with the participants, it was found that gender, though not part of the objectives of this study, did not influence the preferences of the selected undergraduate students of the University of Ibadan to Nollywood films. In other words, the preferences of undergraduate students for Nollywood films did not differ by gender.

\section{Reasons for Undergraduates' Preference for Nollywood English Films}

In respect to the second research question raised, the participants interviewed reported reasons why they preferred English Nollywood films to regional ones despite their linguistic realities. The reasons, emanating from the thematic analysis of the field-notes, could be categorised into repetition, production quality and creativity.

Repetition. The findings of this study revealed that English Nollywood films are not as repetitive in content, concepts, thematic presentation and didactic lessons like most of the regional films. The interviewees reported that they preferred English Nollywood films because each film seems to present new concepts, contents, themes and didactic lessons, unlike the regional ones in which three to four films could be a repetition of the same content, concept, theme and lessons. As a participant averred, 'there is no point watching a film that you know would repeat what you've watched in a film'". All the participants seemed to equivocally aver that regional Nollywood films do not present content, concept, themes and didactic lessons that could fascinate their reception.

Production Quality. Another reason shown by the multilingual undergraduates for their preference for English Nollywood films was the production quality of the films. They reported that Nollywood English film, though not with the same quality as the foreign films, to a great extent have stepped up in their production standard than the regional ones. The English Nollywood producers now make use of sophisticated equipment that would make their films action-packed and events real to life. Such is lacking in most regional Nollywood films. Interestingly, a participant confirmed that ". ...events and actions in many Yoruba films piss me off" because ". ...they are most times not real to life'". This is as a result of the use of equipment that is of low quality for production and post-production. Some of the interviewees cited examples of regional Nollywood films that have evidence of low-quality equipment. It is either the editing is poorly done or production errors are arising from unprofessionalism of the members of crew like continuity, costumier, make-up, set, lighting and so on. However, the English Nollywood producers have acquired the knowledge of modern technologies in film making and production.

Creativity. This is another sub-theme emanating from the field-notes on why the selected multilingual undergraduate preferred English Nollywood films to the regional ones. This issue of creativity in Nollywood film is hinged on the previously discussed points. The participants reported that they preferred English Nollywood films to regional ones because English Nollywood 
producers are more creative in content, concepts, thematic presentation and production than the regional Nollywood producers. Lack of such creativity in most regional Nollywood films normally result in their unnecessary repetition of content, concept, themes and didactic lessons, and undue replication of the same content in many films. "...Many times, it is only titles that differentiate one Yoruba film from the other...', a participant observed. " ...I can tell what's in a Yoruba film by its title alone...", another participant averred. Thus, themes and messages in regional Nollywood films are more predictable than the English Nollywood film. Hence, the undergraduates selected for the interview showed a preference for English Nollywood films. Similarly, the Nollywood English films are more creative in presenting events, directing actions, continuity, costuming, make-up and other technical issues. These and many more make English Nollywood less predictable than the regional ones.

However, two of the participants, whom both showed mild preferences for regional Nollywood films produced in indigenous languages apart from their mother tongue, reported that they preferred such movies because they learn more sets of vocabulary and cultures of such languages in their respective films. Hence, the reason why any multilingual Nigerian might prefer regional Nollywood films may be as a result of the quest to learn Nigerian languages and cultures. This is because region-based movies are highly produced in regional languages and many times promote the culture and traditions of the region in question. For instance, a participant who is an Igbo descent and who also understand Yoruba, claimed to like Yoruba films because they increase his knowledge of the Yoruba language usage and the practice of Yoruba culture.

From the foregoing, it could be extrapolated that the reasons for this undergraduates' high preference for English Nollywood films and mild preference for regional Nollywood films, were far from ethnicity. Even though the undergraduates selected were linguistically attached to more than one ethnic groups in Nigeria, they showed a preference for English Nollywood films over and above the regional ones. This shows that ethnic mind-set may not come to play when the issue is film reception, as entertainment as well as content and concept satisfactions, among others, would have much more to say.

\section{Discussion}

Findings related to the first research question revealed that the selected multilingual undergraduates were fans of Nollywood films, though they showed a preference for English Nollywood films above the regional ones produced in indigenous languages. These findings corroborate the works of Akpabio (2012), Elegbe and Fadipe (2017), Umezinwa (2012) and Okeoma (2012), whom all found that Nigerians are dire-hard fans of Nollywood movies, though in varying degrees and based on varying reasons. However, this present study is different from theirs because it revealed that undergraduates who are multilingual showed a preference for English Nollywood films above the regional ones. This difference is hinged on the focus of this present study and the work of previous scholars.

Whereas, it is pertinent to note that the findings of this present study, as it relates to Nigerians' preferences for Nollywood, negated an aspect of the findings of Onuzilike (2016) who found that Nigerians in South Africa showed disfavour for the reality of Nollywood films. This could be because Onuzilike studied Nigerian films as a whole and not in a dichotomy of English and Regional Nollywood as this present study does. Onuzilike audience's disfavour for Nollywood must have been influenced by many regional Nollywood films and not English Nollywood. This study also found that male and female multilingual undergraduate students of the University of Ibadan did not differ in their preferences for English and/or the regional Nollywood films. This 
negates the findings of Adeleke (1995) who found that Yoruba film audience was dominated by male youths.

The finding of this present study, as it relates to the second research question, revealed that ethnicity did not influence undergraduates' preferences for Nollywood, as their reception preference for English Nollywood above the regional ones were determined by the repetition of concept, content, theme and didactic lessons, production quality and creativity. While regional Nollywood makes undue repetitions and replications of the same concept, content, theme and lessons in differently-titled films, the English Nollywood films present such creatively. As such English Nollywood are of higher quality by content, concept and production.

This finding corroborates the findings of Onuzilike (2016) who also reported that Nigerian audience of Nollywood in South Africa disfavoured the reality of Nollywood film because of its repetition, poor quality and supernatural. Whereas, the finding negates the work of Akpabio (2007), who reported that Nigerian had a positive attitude to Nollywood despite its negative themes. However, the findings of this present study have demonstrated that Nollywood is an important index that could be used to propagate national consciousness and development in Nigeria, just as Umar and Mathew (2014) have also averred.

\section{Conclusion}

This paper has investigated the preference of multilingual undergraduates for English and regional Nollywood to ascertain if ethnic mindset has influence. Based on the results and the findings discussed, it could be concluded that ethnicity does not influence Nollywood reception preferences among multilingual undergraduates of the University of Ibadan, as the reasons for their preferences, according to the thematic analysis of the filed notes, were far from ethnicity. Despite their linguistic experience, they would rather watch an English Nollywood film than watch a regional one, which is flawed with repetitions of concepts, content, themes and didactic lessons as well as poor production and lack of creativity. This could also be partially accounted for by their linguistic reality, which predisposes them to be affiliated to more than one ethnic group. Language is intrinsically related to thoughts and hence, behaviour. Therefore, multilingual individuals may not see an ethnic group or their films better than the other. Conclusively, Nollywood could be harnessed in championing the goal of 'nigerianess' and national consciousness, thereby discouraging ethnic disparity mind-sets among Nigerians.

\section{Recommendations}

Based on the findings of this study, the researcher hereby recommends that:

1. The Federal Ministry of Information and Culture should give more support to the Nigerian Film Industry so that they can perform effectively, their unifying role among others.

2. Nollywood English filmmakers should use more of their movies to showcase the nature of Nigeria's unity in diversity to orientate audience on why they should see themselves as a single entity rather than people of a different race as it were.

3. Nigerian English films that preach Nigeria's unity in diversity should be frequently shown to in-school adolescents during their extra/co-curricular activities to enable them to grow into national consciousness rather than ethnicity.

4. Government and academic institutions should make efforts in ensuring that Nigerian multilingual language education policy is fully implemented. 
5. The producers of regional films should improve their production quality to sustain their local audience.

\section{References}

Adeleke, D. (1995). Audience reception of Yorùbá films: Ìbàdàn as a case study [Unpublished doctoral dissertation]. University of Ibadan, Ibadan, Nigeria.

Adeyinka, A. A., \& Akinsola, I. T. (2017, October 9-13). Language diversity and the problem of ethnicity in Nigeria: Any solution in sight? [Paper presentation]. Annual National Conference of the Yoruba Studies Association of Nigeria (YSAN), University of Ibadan, Ibadan.

Ahmed, M. (2016). Ethnicity, identity and group vitality: A study of Burushos of Srinagar. Journal of Ethnic and Cultural Studies, 3(1), 1-10.

Akpabio, E. (2007). Attitude of audience members to Nollywood films. Nordic Journal of African Studies, 16(1), 90-100.

Akpan, L. (2018). The political undertone in the development of nomadic education in Africa: Lessons from Nigeria. American Journal of Qualitative Research, 2(1), 1-21.

Alamu, O. O. (2010). Aesthetics of Yorùbá Film. Lingua-Culture Contextual Studies in Ethnic Conflicts of the World (LiCCOSEC), Research Institute for World Languages, Osaka University, Japan.

Alawode, S. O., \& Fatonji, S. S. (2013, April 24-26). Ritualism in Nigerian home videos [Proceedings, pp. 62-72]. 1st Annual International Interdisciplinary Conference, AIIC, Azores, Portugal.

Bakalar, B. (2017). Understanding the whole student: holistic multicultural education [Book Review]. Journal of Ethnic and Cultural Studies, 4(2), 96-98.

Blench, R. (2012). An atlas of Nigerian languages ( $3^{\text {rd }}$ ed.). Cambridge CB1 2AL.

Clyne, M. (2007). Multilingualism. In F. Coulmas (Ed.), The handbook of sociolinguistics. Blackwell Publishing.

Ekwuazi, H. (1991). Film in Nigeria (2nd ed.). Jos: Nigeria Film Corporation.

Elegbe, O., \& Fadipe, I. A. (2017). Promoting cultural and social values in Yoruba Nollywood movies. Africology: The Journal of Pan African Studies, 10(2).

Emenanjo, N. (2002, April 16-20). Language policies and cultural identities. World Congress on Language Policy, Barcelona.

Ethnologue. (2019). Ethnologue: Languages of the world. Retrieved April 2, 2019, https://www.ethnologue.com/country/NG

Federal Government of Nigeria. (2004). National Policy of Education (4 $4^{\text {th }}$ ed.). NERDC.

Kachru, B. (1986). Code-mixing, style repertoire and language variation: English in Hindu poetic creativity. World Englishes, 8(3).

Nnoli, O. (1978). Ethnic Politics in Nigeria (Rev. ed. 2008). Fourth Dimension Publishers.

Okeoma, F. C. (2012). A study of the influence of home movies on the dressing patterns of students of tertiary institutions in Abia State [Master's thesis]. University of Nigeria, Nsukka.

Olayiwola, A. (2011). Nollywood at the borders of history: Yoruba travelling theatre and video film development in Nigeria. The Journal of Pan African Studies, 4(5), 183-195.

Ọmọlọlá, B. (2013).The study of oral tradition in Yorùbá movies [Master's thesis]. University of South Africa.

Onuzulike, U. (2016). Audience reactions to the different aspects of Nollywood movies. Cinej Cinema Journal, 5(2). http://cinej.pitt.edu 
Osaghae, E. E. (1995) Structural adjustment and ethnicity in Nigeria. Nordic African Institute.

Ozfidan, B. \& Burlbaw, L. (2016). Perceptions of Bilingual Education Model in Spain: How to Implement a Bilingual Education Model in Turkey. Journal of Ethnic and Cultural Studies, $3(1), 49-58$.

Ukiwo, U. (2005). On the study of ethnicity in Nigeria. Centre for Research on Inequality, Human Security and Ethnicity (CRISE No. 12), United Kingdom: Queen Elizabeth House, University of Oxford.

Umar, B. N., \& Mathew, J. (2014). Film/video industries as channels of communication and development. New Media \& Mass Communication, 21,16-22.

Umezinwa, G. N. (2012). Nigerian home movies: The perception of Nnamdi Azikiwe University students [Master's thesis]. Awka: Nnamdi Azikiwe University.

WorldAtlas. (2019). Nigeria. Retrieved from www.worldatlas.com

Manuscript received March 25, 2020

Final revision received April 17, 2020

Accepted April 23, 2020 